\title{
The place of vericiguat in the landscape of treatment for heart failure with reduced ejection fraction
}

\author{
Alberto Aimo ${ }^{1,2}(\mathbb{0})$. Vincenzo Castiglione ${ }^{1}$. Giuseppe Vergaro ${ }^{1,2} \cdot$ Giorgia Panichella $^{1} \cdot$ Michele Senni $^{4}$. \\ Carlo Mario Lombardi ${ }^{3} \cdot$ Michele Emdin $^{1,2}$
}

Accepted: 8 July 2021 / Published online: 21 July 2021

(C) The Author(s) 2021

\begin{abstract}
The significant morbidity and mortality associated with heart failure with reduced (HFrEF) or preserved ejection fraction (HFpEF) justify the search for novel therapeutic agents. The nitric oxide (NO)-soluble guanylate cyclase (sGC)-cyclic guanosine monophosphate (cGMP) pathway plays an important role in the regulation of cardiovascular function. This pathway is disrupted in HF resulting in decreased protection against myocardial injury. The sGC activator cinaciguat increases cGMP levels by direct, NO-independent activation of sGC, and may be particularly effective in conditions of increased oxidative stress and endothelial dysfunction, and then reduced NO levels, but this comes at the expense of a greater risk of hypotension. Conversely, sGC stimulators (riociguat and vericiguat) enhance sGC sensitivity to endogenous NO, and then exert a more physiological action. The phase 3 VICTORIA trial found that vericiguat is safe and effective in patients with $\mathrm{HFrEF}$ and recent $\mathrm{HF}$ decompensation. Therefore, adding vericiguat may be considered in individual patients with $\mathrm{HFrEF}$, particularly those at higher risk of HF hospitalization; the efficacy of the sacubitril/valsartan-vericiguat combination in HFrEF is currently unknown.
\end{abstract}

Keywords Heart failure $\cdot$ Soluble guanylate cyclase $\cdot$ Cyclic guanosine monophosphate $\cdot$ Treatment $\cdot$ Vericiguat

Heart failure (HF) affects over 20 million people worldwide, and its prevalence is increasing because of the population ageing and the better outcome after acute cardiovascular events [1]. Many therapeutic options are now available for HF with reduced EF (HFrEF). First, the success of early clinical trials established angiotensin-converting enzyme inhibitors (ACEi), angiotensin receptor blockers (ARBs), beta-blockers, and MRA as the foundation for drug treatment of HFrEF [1, 2]. Afterwards, ivabradine [3] and, most importantly, sacubitril/valsartan [4] were added to the list

Alberto Aimo

a.aimo@santannapisa.it; aimoalb@ftgm.it

1 Institute of Life Sciences, Scuola Superiore Sant'Anna, Piazza Martiri della Libertà 33, Pisa, Italy

2 Cardiology Division, Fondazione Toscana Gabriele Monasterio, Piazza Martiri della Libertà 33, Pisa, Italy

3 Department of Medical and Surgical Specialties, Radiological Sciences, and Public Health University and Civil Hospital, Brescia, Italy

4 Cardiovascular Department \& Cardiology Unit, ASST Papa Giovanni XXIII, Bergamo, Italy of disease-modifying therapies. Finally, sodium-glucose cotransporter 2 inhibitors (SGLT2i) empagliflozin [5] and dapagliflozin $[6,7]$, the cardiac-specific myosin activator omecamtiv mecarbil [8], and the soluble guanylate cyclase (sGC) stimulator vericiguat [9] were found to improve outcomes in HFrEF even on the background of a standard therapy with ACEi/ARB, beta-blockers, and MRA. Among the newer therapies, sacubitril/valsartan modulates the neurohormonal imbalance characteristic of HF by acting directly on the natriuretic peptide system. All the other drugs have different mechanisms of action, with vericiguat directly acting on cGMP second messenger, SGLT2i, targeting the kidney and possibly also the heart [10], and omecamtiv mecarbil enhancing cardiac inotropism without increasing oxygen consumption or calcium levels in cardiomyocytes [11].

The emerging challenge of HFrEF treatment is to tailor the therapeutic strategy on each individual patient, namely to identify the combination of treatments with the greatest benefit (in terms of survival, but also quality of life) while minimizing the adverse events (AEs). In this review, we analyze current evidence about vericiguat trying to identify its place in the changing landscape of HFrEF treatment. 


\section{Mechanism of action of therapies targeting the NO-sGC-cGMP pathway}

Nitric oxide (NO) is produced by endothelial NO synthase (eNOS), which is induced by laminar flow and shear stress [12]. NO diffuses to neighbouring cells and binds to the haeme group of sGC, which synthesizes cGMP, then activating protein kinase $\mathrm{G}(\mathrm{PKG})$. Proteins phosphorylated by $\mathrm{PKG}$ in the heart and vessels promote diastolic relaxation; improve coronary blood flow; inhibit the development of inflammation, hypertrophy, and fibrosis in response to cardiac damage; and improve ventricular-arterial coupling [13]. The heart expresses 7 phosphodiesterase (PDE) isoforms, which inactivate cGMP to GMP [14]. PDE3 inhibitors, such as milrinone and enoximone, are used in acute HF (AHF), and PDE5 inhibitors, such as sildenafil and udenafil, improve contractile function in systolic HF, blunt left ventricular (LV) hypertrophic remodelling, reduce myocardial infarct size, and suppress ventricular arrhythmias [15], although both classes do not ameliorate the outcome of HF patients [16]. Finally, natriuretic peptides (NPs), most notably atrial NP (ANP) or B-type NP (BNP), exert their biological effects through transmembrane receptors (NR-A and NR-B) with GC activity (particulate GC, pGC) [17], while NR-C receptors act as clearance receptors, decreasing plasma NP concentration, together with enzymatic cleavage by vasopeptidases like neprilysin (NEP) [18].

In HFrEF, impaired LV systolic function leads to tissue hypoperfusion, which causes inflammation and oxidative stress, leading to decreased NO bioavailability and cGMP deficiency [19]. The cGMP deficiency indeed has deleterious effects on the heart, kidneys, and vessels (including the pulmonary circulation), which may contribute to $\mathrm{HF}$ progression [13]. A blunted response to NPs is commonly observed in HFrEF, which may be due to several mechanisms including altered production or clearance of active NPs, their binding to membrane receptors, or intracellular effects [17]. By acting on a downstream target of the NOsGC-cGMP pathway, sGC modulators may circumvent NP resistance more effectively than other therapeutic strategies aiming to enhance NP concentration, such as the administration of pharmacological doses of recombinant BNP (nesiritide, ularitide), associated with worsening renal function and no effect on outcome.

The sGC activator cinaciguat increases cGMP levels by direct, NO-independent activation of sGC, with a high risk of hypotension [20]. Conversely, sGC stimulators enhance sGC sensitivity to endogenous NO, which possibly explains their neutral effects on blood pressure. While the sGC stimulator riociguat has a shorter half-life requiring 3 administrations per day [21], vericiguat has a more favourable pharmacology.

\section{Pharmacology of vericiguat}

Vericiguat is a weakly basic drug with a low water solubility and high intestinal permeability (class II according to the Biopharmaceutics Classification System) [22]. In healthy humans, vericiguat ( $\leq 10 \mathrm{mg}$, immediate-release [IR] tablets) is rapidly absorbed (median time to reach maximum plasma concentration $\leq 2.5 \mathrm{~h}$ in the fasted state) with 18-22 h half-life. Pharmacokinetic studies reported no deviation from dose proportionality or unexpected accumulation [23]. Administration of vericiguat $5 \mathrm{mg}$ IR tablets with food increases bioavailability up to $93 \%$ (about $19 \%$ increase compared to fasted state), reduces pharmacokinetic variability, and prolongs absorption relative to the fasted state [23]. Vericiguat has about $98 \%$ plasma protein binding, with serum albumin being the main carrier, and is a lowclearance drug $(1.6 \mathrm{~L} / \mathrm{h}$ in healthy volunteers and $1.3 \mathrm{~L} / \mathrm{h}$ in patients with HFrEF) [27]. Beyond the titration regimen, no further dose adjustment is recommended in patients with estimated glomerular filtration rate (eGFR) down to $15 \mathrm{~mL} /$ $\min / 1.73 \mathrm{~m}^{2}$ or those with mild-to-moderate liver disease [9]. In healthy human subjects, $53 \%$ and $45 \%$ of an administered dose is excreted via the urine and faeces, respectively. The main metabolic pathway of vericiguat is glucuronidation via uridine diphosphate-glucuronosyltransferase (UGT) 1A9 and 1A1 [24, 25]. Further in vitro studies with human liver microsomes indicate that vericiguat has no inhibitory effects on the major cytochrome P450 (CYP) isoforms [24], UGT isoforms, or major transport proteins [25]. This denotes a small potential for pharmacokinetic interactions, as confirmed by 10 phase 1 studies searching for possible interactions with drugs that affect intestinal $\mathrm{pH}$ and $\mathrm{NO}$ signalling, inhibit or induce metabolic pathways, or common cardiovascular drugs [25].

\section{Vericiguat in HFrEF: clinical trials}

In the setting of HFrEF, vericiguat has been investigated in phase 2 (SOCRATES-REDUCED) and phase 3 trials (VICTORIA) (Table 1). Both these trials focused on patients with a high risk of decompensation, where the diuretic and natriuretic effects achieved by $\mathrm{sGC}$ stimulation were expected to produce the greatest benefit.

SOCRATES-REDUCED enrolled 456 patients with $\mathrm{LV}$ ejection fraction $(\mathrm{LVEF})<45 \%$ and a recent episode of HF decompensation, defined by worsening HF symptoms requiring hospitalization or outpatient administration of intravenous diuretics, signs of congestion, and elevated NP levels (BNP $\geq 300 \mathrm{ng} / \mathrm{L}$ or NT-proBNP $\geq 1000 \mathrm{ng} / \mathrm{L}$; for patients in atrial fibrillation $[\mathrm{AF}], \mathrm{BNP} \geq 500 \mathrm{ng} / \mathrm{L}$ or NT-proBNP $\geq 1600 \mathrm{ng} / \mathrm{L}$ ), excluding those with 
Table 1 Efficacy and safety of vericiguat: evidence from clinical trials

\begin{tabular}{|c|c|c|c|c|c|}
\hline Study ${ }^{\text {ref }}$ & Setting & Patient $\mathrm{n}$ & Treatment arms & Efficacy & Safety \\
\hline $\begin{array}{l}\text { SOCRATES- } \\
\text { REDUCED } \\
{[26]}\end{array}$ & $\begin{array}{l}\text { HF, LVEF }<45 \%, \\
\mathrm{BNP} \geq 300 \mathrm{ng} / \mathrm{L} \\
(\geq 500 \mathrm{ng} / \mathrm{L} \text { if } \mathrm{AF}) \text { or } \\
\mathrm{NT}-\mathrm{proBNP} \geq 1000 \mathrm{ng} / \mathrm{L} \\
(\geq 1600 \mathrm{ng} / \mathrm{L} \text { if } \\
\mathrm{AF}),<4 \text { weeks from } \mathrm{HF} \\
\text { decompensation }\end{array}$ & 351 & $\begin{array}{l}\text { Vericiguat ( } 1.25 \mathrm{mg} \text {, } \\
2.5 \mathrm{mg}, 5 \mathrm{mg}, 10 \mathrm{mg} \\
\text { daily) for } 12 \text { weeks vs. } \\
\text { placebo }\end{array}$ & $\begin{array}{l}\text { Pooled vericiguat vs. } \\
\text { placebo: no significant } \\
\text { difference in } \Delta \log (\mathrm{NT}- \\
\text { proBNP) from baseline to } \\
\text { week } 12(p=0.15)\end{array}$ & $\begin{array}{c}\text { Any AE: } 71.4 \% \text { vericiguat } \\
10 \mathrm{mg}, 77.2 \% \text { placebo }\end{array}$ \\
\hline VICTORIA (9) & $\begin{array}{l}\text { HF, NYHA II-IV, } \\
\text { LVEF }<45 \%, \\
\text { BNP } \geq 300 \mathrm{ng} / \mathrm{L} \\
(\geq 500 \mathrm{ng} / \mathrm{L} \text { if } \mathrm{AF}) \text { or } \\
\text { NT-proBNP } \geq 1000 \mathrm{ng} / \mathrm{L} \\
(\geq 1600 \mathrm{ng} / \mathrm{L} \text { if } \mathrm{AF}), \\
\text { HF hospitaliza- } \\
\text { tion }<6 \text { months or } \\
\text { worsening HF requiring } \\
\text { iv diuretics }<3 \text { months }\end{array}$ & 5050 & $\begin{array}{l}\text { Vericiguat (target dose } \\
10 \mathrm{mg} \text { daily) vs. placebo }\end{array}$ & $\begin{array}{l}\text { Primary endpoint }(\mathrm{CV} \\
\text { death or HF hospitaliza- } \\
\text { tion): HR } 0.90(0.82- \\
0.98) \\
\text { HF hospitalization: HR } \\
0.90(0.81-1.00) \\
\text { Death or HF hospitaliza- } \\
\text { tion: HR } 0.90(0.83-0.98)\end{array}$ & $\begin{array}{l}\text { Symptomatic hypotension: } \\
\text { 9.1\% vericiguat vs. } 7.9 \% \\
\text { placebo }(p=0.12) \\
\text { Syncope: } 4.0 \% \text { vs. } 3.5 \% \\
\quad(p=0.30) \\
\text { Anaemia: } 7.6 \% \text { vs. } 5.7 \% \\
\text { (serious AEs in } 1.6 \% \text { vs. } \\
0.9 \%)\end{array}$ \\
\hline
\end{tabular}

6MWD 6-min walking distance, $A E$ adverse event, $A F$ atrial fibrillation, $B N P$ B-type natriuretic peptide, $B P$ blood pressure, $C I$ confidence interval, $C V$ cardiovascular, $H F$ heart failure, $H R$ hazard ratio, $K C C Q-C C S$ Kansas City Cardiomyopathy Questionnaire Clinical Summary Score, $K C C Q-C C S$ Kansas City Cardiomyopathy Questionnaire Physical Limitation Score, $L A V$ left atrial volume, $L V E F$ left ventricular ejection fraction, NT-proBNP N-terminal pro-B-type natriuretic peptide, NYHA New York Heart Association, SOCRATES-REDUCED SOluble guanylate Cyclase stimulatoR in heArT failurE patientS with REDUCED EF, VICTORIA Vericiguat Global Study in Subjects with Heart Failure with Reduced Ejection Fraction

eGFR $<30 \mathrm{~mL} / \mathrm{min} / 1.73 \mathrm{~m}^{2}$ and systolic blood pressure $<110$ or $\geq 160 \mathrm{mmHg}$. Patients were randomized to 5 arms (target maximal doses of $1.25 \mathrm{mg}, 2.5 \mathrm{mg}, 5 \mathrm{mg}$, and $10 \mathrm{mg}$ once daily or placebo). Only $77 \%$ of patients completed the 12 -week follow-up, and $72 \%$ of patients randomized to the highest dose reached the target of vericiguat $10 \mathrm{mg}$ daily. The change in log-transformed N-terminal fraction of pro-BNP (NT-proBNP) over 12 weeks did not differ significantly in the pooled vericiguat group and the placebo arm, while the exploratory comparison between vericiguat $10 \mathrm{mg}$ and placebo achieved statistical significance $(p=0.048)$. Patients on the highest vericiguat dose displayed also a greater increase in $\operatorname{LVEF}(p=0.02)$. Vericiguat therapy did not seem to affect haemodynamic function and appeared safe, with lower rates of serious AEs than placebo. A similar proportion of AEs was observed in the pooled vericiguat group and the placebo arm [26]. A post hoc analysis showed that vericiguat treatment was also associated with decrease in plasma high-sensitivity C-reactive protein and serum uric acid. This effect was dose-dependent and most prominent in the highest dose group [27].

The VICTORIA trial enrolled patients with LVEF $<45 \%$, a HF decompensation requiring hospitalization over the previous 6 months, and/or intravenous diuretics $<3$ months $[9,28]$ and elevated circulating NPs (the same cutoffs as in SOCRATES-REDUCED trial) [29]. A total of 5050 patients were enrolled $(76 \%$ men; $60 \%$ of patients were on triple medical therapy with a beta-blocker; a MRA; and either an ACEi, an ARB, or a sacubitril-valsartan [10\%]) [9, 28], and randomized to vericiguat $2.5 \mathrm{mg}$ once daily, up-titrated to $5 \mathrm{mg}$ and then $10 \mathrm{mg}$ at 2 -week intervals, or placebo. Over a median 10.8-month follow-up, patients on vericiguat had a lower incidence of cardiovascular death or first HF hospitalization (hazard ratio [HR] 0.90, 95\% confidence interval [CI] $0.82-0.98 ; p=0.02$ ), with a number needed to treat of around 24 . These results were driven by a lower incidence of first HF hospitalization (HR 0.90, 95\% CI 0.81-1.00), associated with a reduced number of HF hospitalizations (HR $0.91,95 \%$ CI $0.84-0.99 ; p=0.02$ ). Vericiguat seems less effective in patients in the highest quartile of NT-proBNP levels ( $>5314 \mathrm{ng} / \mathrm{L})$, those aged $\geq 75$ years, with worse renal function (eGFR $15-30 \mathrm{~mL} / \mathrm{min} / 1.73 \mathrm{~m}^{2}$ ), or LVEF $40-45 \%$, although the trial was underpowered for these subgroup analyses [9]. The rates of symptomatic hypotension or syncope did not differ significantly between patients on vericiguat or placebo. Anaemia developed more often in patients on vericiguat than placebo, although it was rarely classified as a serious AE. Overall, serious AEs occurred in a similar proportion of patients in the 2 groups. Drug tolerability was further confirmed by an $89 \%$ rate of target dose achievement [9].

In some post hoc analyses, the superior efficacy of vericiguat over placebo was confirmed for NT-proBNP levels at randomization up to $8000 \mathrm{ng} / \mathrm{L}$ [30]. Furthermore, vericiguat reduced the primary endpoint in all subgroups identified by the time from prior HF hospitalization (less than 3 months, 3 to 6 months, or need for intravenous diuretics $<3$ months without hospitalization). Even the safety profile of vericiguat 
did not change across these categories [31]. Therefore, vericiguat prescription does not seem to require further patient phenotyping beyond the inclusion and exclusion criteria of the VICTORIA trial.

\section{Vericiguat in HFrEF: indirect comparisons with other drugs}

While a comparison of HR values for the primary and secondary endpoints might suggest a lower efficacy of vericiguat compared to sacubitril/valsartan (in PARADIGM$\mathrm{HF}$ ) or dapagliflozin (in the DAPA-HF trial), the annualized event rate for the primary endpoint was greater for the VICTORIA than for the PARADIGM-HF (4.2 events per 100 patient-years at risk vs. 2.7), and close to the rate observed in DAPA-HF (4.0 events per 100 patient-years). Even the benefit on first HF hospitalization was greater in VICTORIA than that in PARADIGM-HF (3.2 events per 100 patient-years vs. 1.6) and close to DAPA-HF (2.9 events per 100 patientyears) [5]. Nonetheless, these comparisons did not account for heterogeneity and uncertainty around point estimates and did not assess whether the differences in metrics of efficacy achieved statistical significance. A more sophisticated statistical approach as the network meta-analysis (NMA) provides the unique opportunity to compare multiple treatments using indirect comparisons across trials based on a common comparator [32-34]. Our NMA exploring the relative efficacy of sacubitril/valsartan, vericiguat, and SGLT2i did not indicate a significant superiority of one of the examined drug strategies, except for SGLT2i over vericiguat for the endpoint "HF hospitalization". Specifically, therapy with dapagliflozin was not associated with a significant reduction in the risk of cardiovascular death or HF hospitalization and of cardiovascular death alone, as compared to sacubitril/valsartan and vericiguat, and with a trend toward reduced risk of HF hospitalization as compared to sacubitril/valsartan. Despite the mostly non-significant differences, dapagliflozin had a higher surface under the cumulative ranking (SUCRA) score (a synthetic measure of efficacy) than sacubitril/valsartan and vericiguat [35].

\section{Future perspectives}

HF is characterized by a neurohormonal activation aimed at maintaining an adequate tissue perfusion mainly by improving haemodynamics by an increase in arterial pressure and plasma volume, and promoting cardiac remodelling. Although initially compensatory, these mechanisms are ultimately detrimental, fostering HF progression. The renin-angiotensin-aldosterone (RAAS) and sympathetic nervous systems (SNS), acting through the second messenger cyclic adenylate monophosphate (cAMP) at the cellular level, are key players in this pathophysiological context, and therapies targeting these systems (beta-blockers, ACEi/ARBs, MRAs) represent the standard of care for HFrEF [1].

The NO-sGC-cGMP pathway acts as a counterregulatory axis in HF. In particular, NPs counteract the effects of RAAS and SNS by promoting sodium and water excretion and inhibiting cardiac and vascular remodelling by activating cGMP signalling, which, in turn, can reduce cAMP by activating the phosphodiesterase 2 isoform [36]. As a consequence, approaches aimed at potentiating cGMP signalling might act synergistically to the current standard of care of SNS and RAAs inhibitors. Among therapies increasing cGMP, only sacubitril/valsartan and vericiguat improved patient outcome over ACEi/ARB, beta-blockers, and MRA in HFrEF [26, 27, 37-44]. In particular, vericiguat was evaluated in patients with recently decompensated $\mathrm{HF}$ and a high risk of cardiac events, reducing the composite of cardiovascular death and first HF hospitalization over the standard of care. This result was driven by a reduction in HF hospitalizations [9]. Based on preliminary data, the prognostic benefit from vericiguat does not seem to be associated with reverse remodelling [45], contrary to sacubitril/valsartan [41]. The VICTORIA trial was underpowered to assess the effects of combined vericiguat and sacubitril/valsartan therapy. Future research should try to elucidate whether vericiguat or sacubitril/valsartan is more effective compared to the combination of ACEi/ARB, beta-blockers, and MRA in patients with chronic HF. Moreover, the combination of sacubitril/ valsartan and vericiguat deserves consideration as NPs act through pGC, while vericiguat potentiates sGC activity and response to NO. Cardiomyocyte response to sacubitril/valsartan or vericiguat might be additive or even synergic, given that pGC and sGC have different efficacy in terms of PKG activation under baseline conditions and during adrenergic stimulation [42].

SGLT2 $i$ have been recently added to the armamentarium of therapies for stable HFrEF following the striking results in terms of reduced cardiovascular mortality and HF hospitalizations of DAPA-HF and EMPEROR-REDUCED trials $[5,6]$. Although the main apparent target of SGLT2i is the kidney, a direct effect on the heart (e.g., an interaction with the $\mathrm{Na}^{+} / \mathrm{H}^{+}$exchanger 1 at cardiomyocyte level) is likely based on preclinical studies [43]. Given that the postulated mechanisms of action of SGLT2i and other neurohormonal antagonist/modulators, such as sacubitril/valsartan and vericiguat, are distinct, a possible additive effect of these drug classes cannot be excluded. Indeed, subgroup analyses of DAPA-HF and EMPEROR-REDUCED trials showed that SGLT2i beneficial effect on outcome was maintained in patients on sacubitril/valsartan (representing about $11 \%$ and $19 \%$ of the whole cohort, respectively, in the 2 trials) 
$[5,6]$. Based on these premises, some authors have proposed the combination of beta-blockers, ACEi/ARB/ARNI, MRA, and SGLT2i as the new mainstay of treatment for HFrEF [44]; nonetheless, more data are needed to confirm this assumption. On the other hand, no study has currently investigated the additive effect of vericiguat and SGLT2i, or even the combination of the 2 on top of an optimal medical therapy including sacubitril/valsartan. In terms of relative efficacy, our NMA showed that the effect of these 3 drug classes on outcome (cardiovascular death and HF hospitalization) is similar, with the only exception of SGLT2i being superior to vericiguat in terms of risk of HF hospitalization [35]. These results nonetheless do not exclude an additive effect of the 3 drug classes. Moreover, it must be pointed out that, compared to PARADIGM-HF and DAPA-HF, the VICTORIA trial enrolled more fragile patients (older, more symptomatic, with higher NP levels) who had recently recovered from an AHF event; therefore, vericiguat could be a valuable adjunct in this vulnerable group [9]. Accordingly, the recently published update of the Canadian Cardiovascular Society (HF) guidelines suggests considering vericiguat for HFrEF patients just recovered from HF hospitalization on top of a therapy including a beta-blocker, an ACEi/ARB/ ARNI, a MRA and a SGLT2i [45].

LV pump failure is a main feature of HFrEF; however, until recently, no orally taken drug directly acting on cardiac inotropism was available for chronic HFrEF, with the sole exception of beta-blockers. Omecamtiv mecarbil is a novel selective cardiac myosin activator that directly increases LV systolic function. The GALACTIC-HF trial randomized 8256 patients with stable $\mathrm{LVEF} \leq 35 \%$ to either omecamtiv mecarbil or placebo, demonstrating a modest beneficial effect of this drug on the composite endpoint of time to first HF event (hospitalization or urgent visit) or death from cardiovascular causes, without significant differences regarding the separate components of the primary endpoint or the KCCQ score. Notably, about $19 \%$ of patients enrolled in this trial were on sacubitril//valsartan and $<3 \%$ on a SGLT2i, without significant results at the subgroup analyses [8]. Given the modest effect of omecamtiv mecarbil in the whole cohort, no definite conclusion can be made whether this drug class will ever enter the clinical stage and, therefore, whether a combination with other treatments for HFrEF should be even taken into consideration (Fig. 1).

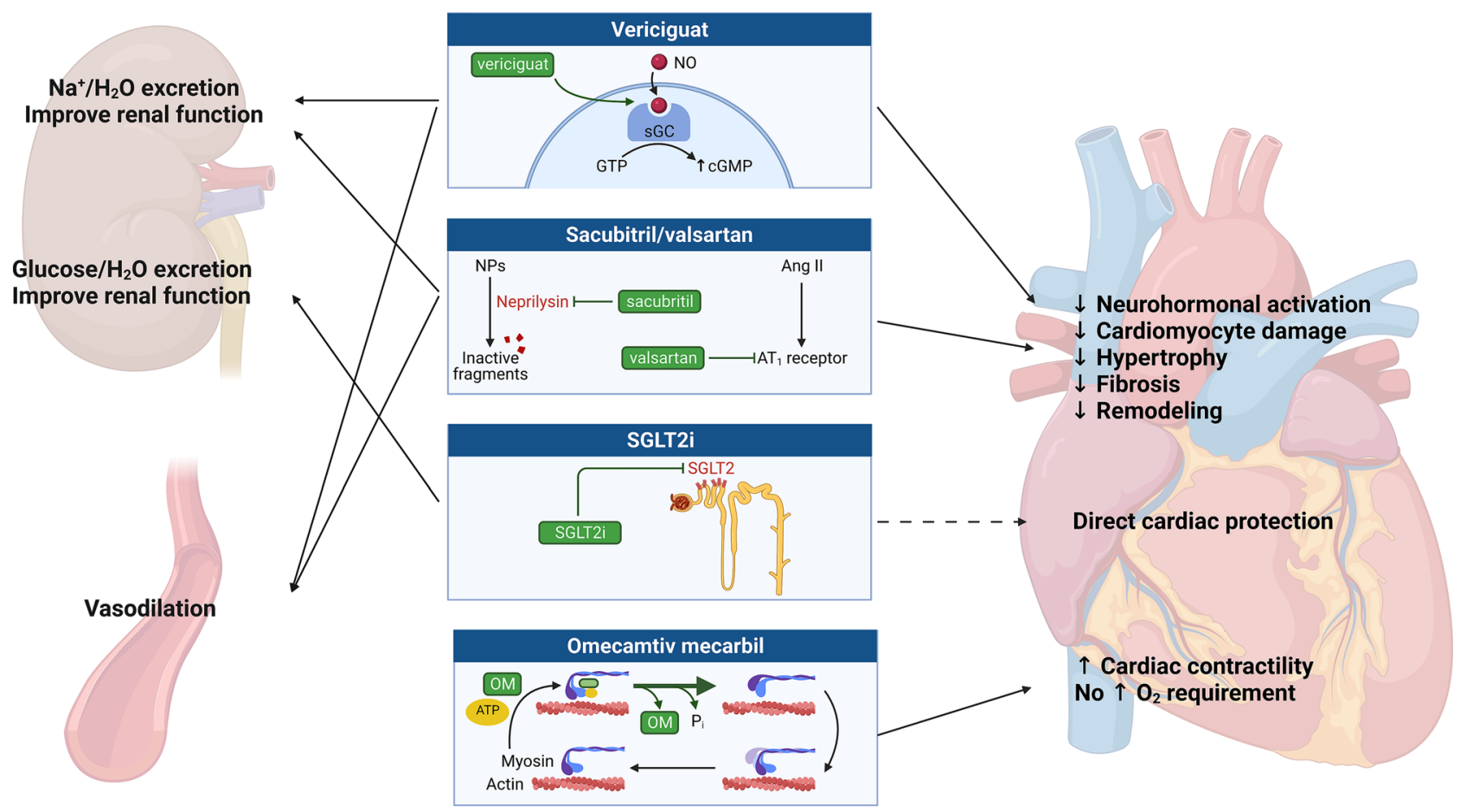

Single therapy: better outcome than standard-of-care

COMBINATION THERAPY?

Fig. 1 Novel therapies for heart failure, their mechanisms of action and final effects. See text for details. Ang, angiotensin; ATP, adenosine triphosphate; cGMP, cyclic guanosine monophosphate; GTP, guanosine triphosphate; NO, nitric oxide; NP, natriuretic peptide; OM, omecamtiv mecarbil; sGC, soluble guanylate cyclase; SGLT2i, sodium-glucose cotransporter 2 inhibitors 
Funding Open access funding provided by Scuola Superiore Sant'Anna within the CRUI-CARE Agreement.

\section{Declarations}

Competing interests M.E. has received consulting fees from Merck; M.M. has received consulting fees from Bayer, Fresenius, Novartis, and Windtree Therapeutics for participation to advisory boards or executive committees of clinical trials; M.S. has received consulting fees from Bayer, Merck, Novartis, Vifor Farma, Abbott, Boehringer Ingelhein, AstraZeneca, Bioventrix, Servier; M.E. and M.S. are the Italian national leader investigators of VICTORIA. The other authors declare no competing interests.

Open Access This article is licensed under a Creative Commons Attribution 4.0 International License, which permits use, sharing, adaptation, distribution and reproduction in any medium or format, as long as you give appropriate credit to the original author(s) and the source, provide a link to the Creative Commons licence, and indicate if changes were made. The images or other third party material in this article are included in the article's Creative Commons licence, unless indicated otherwise in a credit line to the material. If material is not included in the article's Creative Commons licence and your intended use is not permitted by statutory regulation or exceeds the permitted use, you will need to obtain permission directly from the copyright holder. To view a copy of this licence, visit http://creativecommons.org/licenses/by/4.0/.

\section{References}

1. Ponikowski P, Voors AA, Anker SD, Bueno H, Cleland JG, Coats AJ et al (2016) ESC Guidelines for the diagnosis and treatment of acute and chronic heart failure: the Task Force for the diagnosis and treatment of acute and chronic heart failure of the European Society of Cardiology (ESC). Developed with the special contribution of the Heart Failure Association (HFA) of the ESC. Eur J Heart Fail 18(8):891-975

2. Yancy CW, Jessup M, Bozkurt B, Butler J, Casey DE Jr, Colvin MM et al (2017) 2017 ACC/AHA/HFSA focused update of the 2013 ACCF/AHA guideline for the management of heart failure: a report of the American College of Cardiology/American Heart Association Task Force on Clinical Practice Guidelines and the Heart Failure Society of America. J Am Coll Cardiol 70(6):776-803

3. Swedberg K, Komajda M, Böhm M, Borer JS, Ford I, DubostBrama A et al (2010) Ivabradine and outcomes in chronic heart failure (SHIFT): a randomised placebo-controlled study. Lancet (London, England) 376(9744):875-885

4. McMurray JJ, Packer M, Desai AS, Gong J, Lefkowitz MP, Rizkala AR et al (2014) Angiotensin-neprilysin inhibition versus enalapril in heart failure. N Engl J Med 371(11):993-1004

5. Packer M, Anker SD, Butler J, Filippatos G, Pocock SJ, Carson P et al (2020) Cardiovascular and renal outcomes with empagliflozin in heart failure. N Engl J Med 383(15):1413-1424

6. McMurray JJV, Solomon SD, Inzucchi SE, Køber L, Kosiborod MN, Martinez FA et al (2019) Dapagliflozin in patients with heart failure and reduced ejection fraction. N Engl J Med 381(21):1995-2008

7. Zannad F, Ferreira JP, Pocock SJ, Anker SD, Butler J, Filippatos $G$ et al (2020) SGLT2 inhibitors in patients with heart failure with reduced ejection fraction: a meta-analysis of the EMPERORReduced and DAPA-HF trials. Lancet (London, England) 396(10254):819-829
8. Teerlink JR, Diaz R, Felker GM, McMurray JJV, Metra M, Solomon SD et al (2021) cardiac myosin activation with omecamtiv mecarbil in systolic heart failure. N Engl J Med 384(2):105-116

9. Armstrong PW, Pieske B, Anstrom KJ, Ezekowitz J, Hernandez AF, Butler J et al (2020) Vericiguat in patients with heart failure and reduced ejection fraction. $\mathrm{N}$ Eng $\mathrm{J}$ Med

10. Lopaschuk GD, Verma S (2020) Mechanisms of cardiovascular benefits of sodium glucose co-transporter 2 (SGLT2) inhibitors: a state-of-the-art review. JACC Basic Translation Sci 5(6):632-644

11. Teerlink JR, Diaz R, Felker GM, McMurray JJV, Metra M, Solomon SD et al (2020) Omecamtiv mecarbil in chronic heart failure with reduced ejection fraction: rationale and design of GALACTIC-HF. JACC Heart Fail 8(4):329-340

12. Gupta D, Georgiopoulou VV, Kalogeropoulos AP, Marti CN, Yancy CW, Gheorghiade M et al (2013) Nitrate therapy for heart failure: benefits and strategies to overcome tolerance. JACC Heart Fail 1(3):183-191

13. Breitenstein S, Roessig L, Sandner P, Lewis KS (2017) Novel sGC stimulators and sGC activators for the treatment of heart failure. Handb Exp Pharmacol 243:225-247

14. Kim GE, Kass DA (2017) Cardiac phosphodiesterases and their modulation for treating heart disease. Handb Exp Pharmacol 243:249-269

15. Hutchings DC, Anderson SG, Caldwell JL, Trafford AW (2018) Phosphodiesterase-5 inhibitors and the heart: compound cardioprotection? Heart (British Cardiac Soc) 104(15):1244-1250

16. Emdin M, Aimo A, Castiglione V, Vergaro G, Georgiopoulos G, Saccaro LF et al (2020) Targeting cyclic guanosine monophosphate to treat heart failure: JACC review topic of the week. J Am Coll Cardiol 76(15):1795-1807

17. Volpe M, Carnovali M, Mastromarino V (2016) The natriuretic peptides system in the pathophysiology of heart failure: from molecular basis to treatment. Clinical science (London, England 1979). 130(2):57-77

18. Clerico A, Recchia FA, Passino C, Emdin M (2006) Cardiac endocrine function is an essential component of the homeostatic regulation network: physiological and clinical implications. Am J Physiol Heart Circ Physiol 290(1):H17-29

19. Aimo A, Castiglione V, Borrelli C, Saccaro LF, Franzini M, Masi $S$ et al (2019) Oxidative stress and inflammation in the evolution of heart failure: from pathophysiology to therapeutic strategies. Euro J Prevent Cardio 2047487319870344

20. Gheorghiade M, Greene SJ, Filippatos G, Erdmann E, Ferrari $\mathrm{R}$, Levy PD et al (2012) Cinaciguat, a soluble guanylate cyclase activator: results from the randomized, controlled, phase IIb COMPOSE programme in acute heart failure syndromes. Eur J Heart Fail 14(9):1056-1066

21. Bonderman D, Ghio S, Felix SB, Ghofrani HA, Michelakis E, Mitrovic V et al (2013) Riociguat for patients with pulmonary hypertension caused by systolic left ventricular dysfunction: a phase IIb double-blind, randomized, placebo-controlled, doseranging hemodynamic study. Circulation 128(5):502-511

22. Yu LX, Amidon GL, Polli JE, Zhao H, Mehta MU, Conner DP et al (2002) Biopharmaceutics classification system: the scientific basis for biowaiver extensions. Pharm Res 19(7):921-925

23. Boettcher M, Thomas D, Mueck W, Loewen S, Arens E, Yoshikawa K et al (2020) Safety, pharmacodynamic, and pharmacokinetic characterization of vericiguat: results from six phase I studies in healthy subjects. Euro J Clin Pharmacol

24. Follmann M, Ackerstaff J, Redlich G, Wunder F, Lang D, Kern A et al (2017) Discovery of the soluble guanylate cyclase stimulator vericiguat (BAY 1021189) for the treatment of chronic heart failure. J Med Chem 60(12):5146-5161

25. Boettcher M, Gerisch M, Lobmeyer M, Besche N, Thomas D, Gerrits M et al (2020) Metabolism and pharmacokinetic drug-drug interaction profile of vericiguat, a soluble guanylate 
cyclase stimulator: results from preclinical and phase I healthy volunteer studies. Clin Pharmacokinet 59(11):1407-1418

26. Gheorghiade M, Greene SJ, Butler J, Filippatos G, Lam CS, Maggioni AP et al (2015) Effect of vericiguat, a soluble guanylate cyclase stimulator, on natriuretic peptide levels in patients with worsening chronic heart failure and reduced ejection fraction: the SOCRATES-REDUCED Randomized Trial. JAMA 314(21):2251-2262

27. Kramer F, Voss S, Roessig L, Igl BW, Butler J, Lam CSP et al (2020) Evaluation of high-sensitivity C-reactive protein and uric acid in vericiguat-treated patients with heart failure with reduced ejection fraction. Eur J Heart Fail 22(9):1675-1683

28. Pieske B, Patel MJ, Westerhout CM, Anstrom KJ, Butler J, Ezekowitz J et al (2019) Baseline features of the VICTORIA (vericiguat Global Study in Subjects with Heart Failure with Reduced Ejection Fraction) trial. Eur J Heart Fail

29. Armstrong PW, Roessig L, Patel MJ, Anstrom KJ, Butler J, Voors AA et al (2018) A multicenter, randomized, double-blind, placebocontrolled trial of the efficacy and safety of the oral soluble guanylate cyclase stimulator: the VICTORIA trial. JACC Heart Fail 6(2):96-104

30. Ezekowitz JA, O'Connor CM, Troughton RW, Alemayehu WG, Westerhout CM, Voors AA et al (2020) N-terminal pro-Btype natriuretic peptide and clinical outcomes: vericiguat heart failure with reduced ejection fraction study. JACC Heart Fail 8(11):931-939

31. Lam CSP, Giczewska A, Sliwa K, Edelmann F, Refsgaard J, Bocchi E et al (2020) Clinical outcomes and response to vericiguat according to index heart failure event: insights from the VICTORIA Trial. JAMA Cardio

32. Lumley $\mathrm{T}$ (2002) Network meta-analysis for indirect treatment comparisons. Stat Med 21(16):2313-2324

33. Caldwell DM, Ades AE, Higgins JP (2005) Simultaneous comparison of multiple treatments: combining direct and indirect evidence. BMJ (Clinical research ed) 331(7521):897-900

34. Li T, Puhan MA, Vedula SS, Singh S, Dickersin K (2011) Network meta-analysis-highly attractive but more methodological research is needed. BMC Med 9:79

35. Aimo A, Pateras K, Stamatelopoulos K, Bayes-Genis A, Lombardi CM, Passino C et al (2020) Relative efficacy of sacubitril-valsartan, vericiguat, and SGLT2 inhibitors in heart failure with reduced ejection fraction: a systematic review and network meta-analysis. Cardiovasc Drugs Ther
36. Kemp CD, Conte JV (2012) The pathophysiology of heart failure. Cardiovasc Pathol 21(5):365-371

37. Armstrong PW, Pieske B, Anstrom KJ, Ezekowitz J, Hernandez AF, Butler J et al (2020) Vericiguat in patients with heart failure and reduced ejection fraction. N Engl J Med 382(20):1883-1893

38. McMurray JJ, Packer M, Desai AS, Gong J, Lefkowitz MP, Rizkala AR et al (2013) Dual angiotensin receptor and neprilysin inhibition as an alternative to angiotensin-converting enzyme inhibition in patients with chronic systolic heart failure: rationale for and design of the prospective comparison of ARNI with ACEI to Determine Impact on Global Mortality and morbidity in Heart Failure trial (PARADIGM-HF). Eur J Heart Fail 15(9):1062-1073

39. Solomon SD, Rizkala AR, Gong J, Wang W, Anand IS, Ge J et al (2017) Angiotensin receptor neprilysin inhibition in heart failure with preserved ejection fraction: rationale and design of the PARAGON-HF Trial. JACC Heart Fail 5(7):471-482

40. Velazquez EJ, Morrow DA, DeVore AD, Ambrosy AP, Duffy CI, McCague K et al (2018) Rationale and design of the comParIson Of sacubitril/valsartaN versus enalapril on effect on nt-pRo-bnp in patients stabilized from an acute Heart Failure episode (PIONEER-HF) trial. Am Heart J 198:145-151

41. Khan MS, Felker GM, Piña IL, Camacho A, Bapat D, Ibrahim NE et al (2020) Reverse cardiac remodeling following initiation of sacubitril/valsartan in patients with heart failure with and without diabetes. JACC Heart Fail

42. Takimoto E, Belardi D, Tocchetti CG, Vahebi S, Cormaci G, Ketner EA et al (2007) Compartmentalization of cardiac betaadrenergic inotropy modulation by phosphodiesterase type 5 . Circulation 115(16):2159-2167

43. Zelniker TA, Braunwald E (2020) Mechanisms of cardiorenal effects of sodium-glucose cotransporter 2 inhibitors: JACC stateof-the-art review. J Am Coll Cardiol 75(4):422-434

44. Straw S, McGinlay M, Witte KK (2021) Four pillars of heart failure: contemporary pharmacological therapy for heart failure with reduced ejection fraction. Open Heart 8(1)

45. McDonald M, Virani S, Chan M, Ducharme A, Ezekowitz JA, Giannetti N et al (2021) CCS/CHFS heart failure guidelines update: defining a new pharmacologic standard of care for heart failure with reduced ejection fraction. Can J Cardiol 37(4):531-546

Publisher's Note Springer Nature remains neutral with regard to jurisdictional claims in published maps and institutional affiliations. 